\title{
EL CONCEPTO DEL DAÑO MORAL BAJO EL PRISMA DE LA JURISPRUDENCIA
}

\author{
Blanca Casado Andrés \\ Abogada-Doctora en Derecho Civil \\ Email: mbcasado@usal.es
}

\begin{abstract}
RESUMEN: En la actualidad se siguen produciendo debates sobre qué debe entenderse por daño moral, probablemente la abstracción del término sea la causa. No obstante, la autonomía del daño moral y su admisión por los tribunales (desde el año 1912) resulta incuestionable, al igual que su resarcimiento. Nuestros Tribunales no ofrecen una definición de daño moral. Su aportación es meramente práctica, y aunque son numerosas las sentencias que analizan la cuestión de los daños morales, la mayoría se limitan a resolver el caso planteado, con una clara propensión a enumerar los supuestos más significativos en relación a los bienes protegidos y a ampliar el ámbito de este tipo de daños.
\end{abstract}

PALABRAS CLAVE: daño moral, concepto, jurisprudencia, sentencias.

ABSTRACT: At present debates continue taking place on what it must be understood by moral hurt, probably the abstraction of the term is the reason. Nevertheless, the autonomy of the moral hurt and his admission for the courts (from the year 1912) turns out to be unquestionable, as his indemnity. Our Courts do not offer a definition of moral hurt. His contribution is merely practical, and though there are numerous the judgments that analyze the question of the moral hurts, the majority they limit themselves to solving the raised case, with a clear tendency to enumerate the most significant suppositions in relation to the protected goods and to extend the area of this type of hurts.

KEYWORDS: moral hurt, concept, jurisprudence, judgments. 
SUMARIO: 1. Concepciones jurisprudenciales. 1.1. Antecedentes históricos. 1.2. Evolución de nuestra jurisprudencia y su postura ante el daño moral. 1.2.1. Bienes jurídicos lesionados que forman parte del concepto de daño moral (supuestos-tipo). 1.2.2. El concepto de daño moral según algunas sentencias. 2. Conclusiones.

\section{CONCEPCIONES JURISPRUDENCIALES}

\subsection{ANTECEDENTES HISTÓRICOS}

Algunos autores afirman que el daño moral es una creación jurisprudencial ${ }^{1}$. Probablemente, y a falta de normas que lo regulen de manera rotunda y expresa, esta aseveración tenga su origen en la necesidad del Derecho de dar respuesta a los demandantes que reclaman una indemnización cuando se ha producido una situación dañosa ("id quod interest") ${ }^{2}$.

Del daño moral nada dicen ni el Código Civil ni la Constitución Española, si bien son las normas civiles de los Códigos penales vigente e histórico, las que mayor atención han prestado al tema ${ }^{3}$. Al daño moral hacen también referencia algunas leyes

\footnotetext{
${ }^{1}$ BARrientos ZAMORAnO, M., El resarcimiento por daño moral en España y Europa, Ratio Legis, Salamanca, 2007, pág. 31.

${ }^{2}$ La expresión latina "id quod interest" se utiliza por la doctrina moderna para referirse a la obligación consistente en el resarcimiento de daños y perjuicios, que es la auténtica responsabilidad civil. De ahí que durante siglos, el Derecho de daños consistiera en el estudio del interesse, el Tractatus del id quod interest. Lo apunta, Llamas POMBO, E., Cumplimiento por equivalente y resarcimiento del daño al acreedor, Trivium, Madrid, 1999, págs. 186 y 270.
}

${ }^{3}$ YZQuierdo Tolsada, M., Sistema de responsabilidad civil, contractual y extracontractual, Dykinson, Madrid, 2001, págs. 156-157. Al respecto, muy ilustrativa resulta la STS (Sala de lo Penal) de 29 de junio de 1987 (RJ 1987\5018), Pte. Sr. Luis Vivas Marzal, en cuyo FJ $8^{\circ}$ resume el panorama en el orden penal así, declara: “En España, los Códigos Penales del siglo XIX, no se refieren al daño a los perjuicios morales, el Código de 1928, en su artículo 75, prescribe que, en los delitos contra el honor -calumnia, injurias y difamación-, se tendrá muy especialmente en cuenta, para la valoración del daño, el que represente el desprestigio y sufrimiento moral en sí mismo aunque no repercuta en el patrimonio del 
especiales, como es el caso de la Ley Orgánica 1/1982, de 5 de mayo, de protección civil del derecho al honor, a la intimidad y a la propia imagen, la Ley de ordenación y supervisión de los seguros privados o la Ley de Prensa, entre otras. Lo cierto es que a pesar de que lo mencionan, no lo definen ${ }^{4}$.

Y es que este recelo a conceptuar el daño moral se remonta al Derecho romano ${ }^{5}$ : ya en aquella época se planteó la problemática de una posible reparación de los bienes o intereses no patrimoniales, y a falta de normas que lo regulasen, fueron los tribunales romanos a través de la actio iniuriarum o estimatoria, los que acordaron la protección de determinados bienes de naturaleza no patrimonial mediante la concesión de verdaderas indemnizaciones pecuniarias. Con posterioridad, este criterio establecido para las injurias fue seguido por el Edicto de los Ediles que llegó a establecer que la muerte producida por los animales salvajes debía satisfacerse con la cantidad de doscientos sueldos y en caso de lesión corporal se dejaba su estimación a cuanto al juez pareciese bueno y justo (D. 21.2.42) ${ }^{6}$.

La siguiente época relevante para nuestro análisis histórico nos lleva a la legislación alfonsina habida cuenta que la regulación de esta materia es extraordinariamente casuística. En este sentido, el influjo del Derecho romano se manifiesta notablemente en materia de responsabilidad extracontractual. En efecto, si el ordenamiento romano contemplaba la protección de los daños corporales, Las Partidas acogen este planteamiento hasta tal punto que definen el daño como aquel que

ofendido; en el Código de 1932, en la reparación del daño, se ha de tener en cuenta el valor de afección para el agraviado, lo que supone un hito importante en el camino del reconocimiento del resarcimiento del daño moral, y, finalmente, en el artículo 104 del Código Penal de 1944, de modo explícito, se reconoce el derecho a la indemnización de los perjuicios materiales y morales causados al ofendido o a su familia".

${ }^{4} C f r$. Textos legales. En realidad, la normativa reseñada hace hincapié y resalta la obligación de indemnizar los daños inmateriales o morales, pero no existe ningún artículo que establezca la noción del daño moral.

${ }^{5}$ YzQuierdo Tolsada, M., Sistema de ..., op. cit., pág. 157.

${ }^{6}$ GarCía LóPez, R., Responsabilidad civil por daño moral. Doctrina y Jurisprudencia, José Ma Bosh Editor, s.a., Barcelona, 1990, págs. 28 a 32. 
comprende tanto el daño patrimonial como el no patrimonial ${ }^{7}$. Es más, partiendo de la misma influencia romana, la Partida VII, tít. XV, 1. XXIII, en el caso de los daños producidos por animales, dispone "si quedase imperfecto de algún miembro será el resarcimiento al arbitrio del juez, teniendo en cuenta quien es el que recibió el mal y cuál el miembro lesionado”. Por lo tanto, esta Partida proclamaba la indemnización por los daños ocasionados por animales salvajes, es decir, incluiría los gastos de curación y los servicios perdidos (damnum emergens) así como los dejados de prestar (lucrum cesans). Este pasaje será uno de los que más influencia tendrá en nuestro derecho puesto que precisamente estos dos criterios, serán los mismos que la jurisprudencia moderna examinará para la estimación del daño moral $^{8}$.

Efectuado este breve análisis de lo que representó la casuística romana y la de las Partidas, hemos de reseñar que la evolución de la jurisprudencia civil en cuanto al reconocimiento de los derechos que componen el patrimonio moral, ha sido lenta pero en sentido ascendente. Sirva como ejemplo que mientras que el siglo XIX las reclamaciones de daños y perjuicios causados por lesiones contra el honor o la intimidad estaban condenadas al fracaso $^{9}$, en los tiempos contemporáneos es pacíficamente aceptado, tanto por la legislación como por la jurisprudencia, que el daño moral debe ser reparado ${ }^{10}$.

\footnotetext{
${ }^{7}$ García LóPeZ, R., Responsabilidad civil ..., op. cit., pág. 34. Así, la Partida VII, Tít.XV, 1. I define el daño como "empeoramiento o menoscabo, o destrucción que el hombre recibe en sí mismo o, o en sus cosas por culpa de otro", que no puede ser otro que el moral o no patrimonial.
}

${ }^{8}$ García LóPez, R., Responsabilidad civil ..., op. cit., págs. 37-38. La influencia del Digesto y de las Partidas se verá a su vez plasmada en el Código civil de 1851. El Código de García Goyena cita como inspiradores muchos de los preceptos de aquellos textos legislativos y señala que el término daño engloba tanto "el daño que el hombre recibe en si mismo como es sus cosas".

${ }^{9}$ YZQuierdo Tolsada, M., Sistema de ..., cit., pág. 158.

${ }^{10}$ Lasarte Álvarez, C., Principios de derecho civil. Parte general y derecho de la persona", T. I, $6^{a}$ edic., Trivium, Madrid, 1998, pág. 226; SANTOS BRIZ, J., La responsabilidad civil. Derecho sustantivo y derecho procesal, Montecorvo, Madrid, 1970, pág. 155. Sobre este particular, en cuanto a la legislación se refiere, ya anunciaba el autor, que la reparación de los daños morales es posible al amparo del artículo 1902 C.C., y tampoco se excluía de modo absoluto su reparación aun en el campo del incumplimiento de contratos a través del los artículos 1106 y 1107 C.C.; GARCía SERRANO, F. A., "El daño moral en la jurisprudencia civil", $A D C, 1972$, pág. 815. Por cuanto concierne a la jurisprudencia, diferencia con claridad las tres etapas: la primera, en la que no admite la indemnización pecuniaria del daño moral $(v$. $g r$., la STS 11 de marzo de 1899 que resolvió señalando que "los disgustos no son indemnizables"); la segunda, en la indemniza algunos supuestos en cuanto producen repercusiones patrimoniales; y la tercera etapa, en la que se admite el resarcimiento de los daños morales puros, independientemente de las 


\subsection{EVOLUCIÓN DE NUESTRA JURISPRUDENCIA Y SU POSTURA ANTE EL DAÑO MORAL}

A diferencia de la doctrina, nuestra Jurisprudencia civil aborda la problemática del daño moral limitándose a resolver el caso planteado, y a pesar de que el número de sentencias en las que trata la reparación del daño moral es abundante, hemos de concluir que solo en una minoría de ellas el Tribunal Supremo construye una teoría sobre los perjuicios o daños morales ${ }^{11}$. Al margen de estas sentencias, la doctrina sentada en las diferentes resoluciones jurisprudenciales pone de manifiesto la inexistencia de una noción clara del concepto de daño moral ${ }^{12}$.

La primera sentencia en la que de manera expresa el Tribunal Supremo reconoció la existencia de daño moral, fue dictada en fecha 6 de diciembre de $1912^{13}$; ésta célebre sentencia marcará la apertura de una nueva época en nuestra jurisprudencia $^{14}$, si bien es cierto que esta resolución no admitía ampliamente el daño moral, sino sólo aquel que indirectamente tenía consecuencias en el patrimonio de la

repercusiones patrimoniales que se de aquellos se deriven. En idéntico sentido, DE ÁNGEL YAGÜEZ, R., Tratado de Responsabilidad Civil, Civitas, Madrid, 1993, pág. 676.

${ }^{11}$ Por todos, García SERRANO, F. A., “El daño moral ...”, cit., pág. 808.

12 PÉrez Ontiveros Baquero, C., Daño moral por incumplimiento de contrato, Thomson-Aranzadi, Navarra, 2006, pág. 35.

${ }^{13}$ Cfr. Los hechos acontecen cuando el periódico "El Liberal" publicó la falsa noticia por la que daba cuenta de la fuga de un fraile con la hija menor del alcalde de Totana, con la que al parecer y según el diario, llevaba 3 meses manteniendo "una escandalosa sucesión”. Sorprendidos en la entrada de Lorca, por un tío de la quinceañera, el religioso se suicida. La sentencia, sin llegar a definir el concepto de daño moral, se expresa en los siguientes términos: "la honra, el honor y la fama de la mujer constituyen los bienes sociales de su mayor estima, y su menoscabo la pérdida de mayor consideración que pueda padecer en una sociedad civilizada, incapacitándola para ostentar en ella el carácter de depositaria y custodia de los sagrados fines del hogar doméstico, base y piedra angular de la sociedad pública, debiendo por tanto ser apreciados estos daños como uno de los más graves”.

${ }^{14}$ Por todos, Pascual Estevill, L., Derecho de daños, T.II, $2^{\text {a }}$ edic., Bosch, Barcelona, pág. 894. La STS 6 diciembre de 1912, recurrió a la Ley 21, del título 9º de la Partida VII, para reconocer por la vía del art. $1.902 \mathrm{CC}$, el perjuicio y posterior derecho a reparación del honor de una joven a consecuencia de la publicación de una falsa noticia sobre su vida íntima, según acabamos de relatar. 
víctima. Hay que esperar a la STS de 14 de diciembre de 1917 para que este tipo de perjuicio se reconozca en toda su amplitud. En efecto, esta resolución indemnizará por primera vez en nuestro país, un daño moral puro ${ }^{15}$.

A partir de aquí son muchas las sentencias que se suceden y que se aproximan al problema de la indemnización del perjuicio moral pero como hemos enunciado, sin aparente criterio teórico ${ }^{16}$. Se podría afirmar que el Tribunal Supremo, en lugar de establecer un concepto, se ha centrado más en destacar los siguientes aspectos referidos a los daños morales ${ }^{17}$ :

a) Reconoce que no es práctica habitual alegar este tipo de daños pero incluso alegándolos, se relegan a un segundo plano, salvo excepciones.

b) Tiende a ejemplificar los supuestos de daño moral (honor, salud, libertad) huyendo de plantear fórmulas que lo definan.

c) Acentúa su carácter de extrapatrimonialidad en razón al objeto afectado, si bien, no hace coincidir totalmente el objeto del perjuicio moral con la extrapatrimonialidad, puesto que lo reduce a identificarlo con la esfera integrada por los bienes y derechos de la personalidad ${ }^{18}$.

Lo cierto es que casi la totalidad de las sentencias se limitan a pronunciarse sobre el presunto daño moral respecto al caso concreto. No obstante, la multiplicación de los casos en los que se hace procedente esta reparación es tan extensa ${ }^{19}$, que resulta

\footnotetext{
15 Domínguez Hidalgo, C.A., El daño moral, T.I, Editorial Jurídica de Chile, Santiago (Chile), 2000, pág. 369. Esta sentencia concedió la indemnización a un médico que injustificadamente había sido expulsado de su colegio profesional "por el menoscabo causado en la fama y reputación profesional del médico demandante".

${ }^{16}$ GÓMEZ POMAR, F., Daño moral, InDret 1/2000, www.indret.com.

${ }^{17}$ García SERrano, F. A., “El daño moral ...”, cit., págs. 808 a 810.

${ }^{18}$ GARCÍA LÓPEZ, R., Responsabilidad civil ..., op. cit., pág. 97.

19 García Serrano, F. A., “El daño moral ...”, pág. 827. El hecho de que no exista un “número clausus" de supuestos admisibles a la hora de estimar los daños morales, conlleva un riesgo de proliferación de demandas tendentes a reclamar daños morales que a veces son inexistentes.
} 
imposible referir todas las resoluciones judiciales, por lo tanto, y siguiendo las bases sentadas por GARCÍA LÓPEZ ${ }^{20}$ en orden a fijar la postura que mantiene la jurisprudencia respecto a este tipo de daños, agruparemos las sentencias en dos bloques: el primero estará formado por las sentencias que sin ofrecernos un concepto expreso de daño moral, destacan los bienes jurídicos que pueden formar parte de este tipo de daños (supuestos-tipo); mientras que el segundo, lo configurarán las sentencias que se atreven a esbozar un concepto de daño moral.

\subsubsection{BIENES JURÍDICOS LESIONADOS QUE FORMAN PARTE DEL CONCEPTO DE DAÑO MORAL (SUPUESTOS-TIPO):}

Son numerosos los bienes jurídicos que la jurisprudencia ha estimado como integrantes de la noción de daño moral, por lo tanto, resulta inviable fijar un "numerus clausus" en relación a este tipo de bienes. Además, la jurisprudencia se encuentra, en este sentido, en constante renovación y adecuándose a los tiempos. Efectivamente, la nota que caracteriza a nuestros tribunales, es la de constante y reiterada ampliación del ámbito de los daños morales ${ }^{21}$. Al respecto, señalaremos las sentencias más relevantes:

\section{a) En relación al honor en sus distintas manifestaciones:}

\section{El honor personal}

Precisamente la primera sentencia que reconoció la existencia del daño moral (STS 6.12.1912) lo hace respecto a la protección del honor a la mujer ${ }^{22}$. Años más tarde, será la sentencia de la Sala $2^{\mathrm{a}}$ del TS de 24 de octubre de 1959, la que proteja el honor del marido ${ }^{23}$, incluso la STS de 9 de junio de 1969, protege el honor conyugal.

\footnotetext{
${ }^{20}$ GARCÍA LÓPEZ, R., Responsabilidad civil ..., op. cit., págs. 80 y ss.

${ }^{21}$ Por todos, García Serrano, F. A., “El daño moral ...”, locus cit., pág. 824.

${ }^{22} C f r$. Nota a pie de página 14.

${ }^{23}$ Cfr. La sentencia consideró la existencia de daño moral respecto al honor del marido que quedó mancillado, habida cuenta que su esposa le había sido infiel con otro hombre. Manifiesta que "además de ser una ofensa al sentimiento público de honestidad, ataca directamente la dignidad y honor del marido, que al ver mancillado y deshecho su hogar, ha de sufrir la tortura de tan afrentosa situación”.
} 
Otras sentencias, aceptan el daño al honor en toda su amplitud, destacando la STS de 4 de junio de 1962 que declaró que "el artículo 1902 del CC comprende como indemnizables los daños inferidos por lesiones al honor de una persona en toda la gama en que pueda ser estimado”, y la STS de 7 de febrero de 1962, que incluye todas las manifestaciones del sentimiento de estimación de una persona, honor civil, comercial, científico, literario, artístico, profesional, etc. ${ }^{24}$

Este forma de entender el honor cambiará cuando éste sea considerado un derecho fundamental a raíz de la promulgación de la Constitución Española y de la Ley 1/1982, de 5 de mayo, por esta razón, será analizado con mayor detalle en siguientes apartados.

\section{El honor profesional}

Fue la renombrada STS de 14 de diciembre de 1917 la que por primera considera la existencia de daño moral puro respecto al supuesto del menoscabo de la reputación de un médico en el ejercicio de su profesión ${ }^{25}$. Esta sentencia sentó las bases para conceder la indemnización por daños morales en supuestos similares, como fue el caso de la célebre STS de 9 de mayo de 1984, por la que se resarce a un abogado por los daños y perjuicios sufridos al no haber sido incluido en la guía telefónica durante un año, con la repercusión que ello entrañaba ante la incertidumbre de su baja y cesación patrimonial, traducible en menor clientela ${ }^{26}$; o el supuesto que analiza la STS de 21 de octubre de 1996, que resuelve a favor de una compañía artística por los daños y perjuicios causados al no poder representar la obra programada, habida cuenta que el

\footnotetext{
${ }^{24}$ Domínguez Hidalgo, C.A., El daño ..., cit., pág. 371.

${ }^{25}$ Cfr. Nota a pie de pág. 16.

${ }^{26}$ (RJ 1984\2403), Pte. Sr. Carlos de la Vega Benayas. El TS incide que el bien jurídico lesionado es la fama, el honor, la nombradía profesional, calificando a este tipo de daños como "relativamente patrimoniales o indirectos”. En palabras de Domínguez HidAlgO, C.A., El daño ..., locus cit., pág. 384, esta sentencia ha sido señalada unánimemente por la doctrina, como la primera decisión en acoger la indemnización por daño moral en el marco contractual. La autora además, destaca el retraso del pronunciamiento de esta sentencia en orden a la admisión de este daño, en comparación con la responsabilidad delictual (6 de diciembre de 1912).
} 
teatro en el que iban a actuar no se encontraba a su disposición, de conformidad con la cesión que habían acordado ${ }^{27}$.

\section{El honor mercantil}

La consideración de las lesiones al honor de las personas jurídicas se puso de relieve con la añeja STS de 31 de marzo de $1930^{28}$ aunque la postura marcada de manera tan temprana por esta sentencia, será vacilante a lo largo de los años. La cuestión de si las personas jurídicas pueden sufrir daños morales ha sido ampliamente debatida por la doctrina y la jurisprudencia sobre todo teniendo en cuenta el recelo a considerar que las personas jurídicas no eran susceptibles de ser titulares del derecho al honor $^{29}$.

Al margen de este debate, la cuestión parece estar resulta a favor de considerar que también es posible la indemnización por daño moral a las personas jurídicas (en el

27 (RJ 1996\7235), Pte. Sr. Alfonso Villagómez Rodil. Fundamenta esta indemnización basándose en el ataque al prestigio y reputación de la compañía de teatro, así como por la desmoralización del elenco artístico y la defraudación al público aficionado.

${ }^{28}$ Feliu Rey, M. I., ¿Tienen Honor las Personas Jurídicas?, Tecnos, Móstoles (Madrid), 1990, págs. 9 y 25. Por cuanto respecta a la sentencia del Alto Tribunal de 31 de marzo de 1930, se trató de entrar a conocer si una Sociedad a la que se le causaron daños con motivo de la publicación de determinados anuncios en varios periódicos bilbaínos, debía ser o no indemnizada. El Supremo falla a favor de la Mercantil retrotrayéndose a los mismos criterios que había utilizado en la sentencia de 6 de diciembre de 1912, apoyándose en el valor moral y material que representa el crédito y la buena fama para los comerciantes.

29 Rodríguez GUITIAN, A. M., El derecho al honor de las personas jurídicas, Montecorvo, Madrid, 1996, pág. 108. Señala la autora que hay dos posturas doctrinales claramente diferenciadas: los que niegan los daños morales a las personas jurídicas, por entender la noción de daño moral como la lesión a los sentimientos, al sufrimiento o al dolor (concepto subjetivo). Esta corriente doctrinal considera que las personas jurídicas no son titulares del derecho al honor puesto que carecen de una dimensión psicológica, no pueden sufrir ofensas y por lo tanto, tampoco daño moral; y la segunda corriente en la que se englobarían los que mantienen una concepción más amplia de daño moral en el sentido de abarcar los atentados a los derechos de la personalidad (concepto objetivo) y que son los que consideran que la persona jurídica podría pretender legitimación activa para tales daños por entender que no sólo se ocasiona daño moral cuando se sufren sensaciones dolorosas sino también cuando se dificulta o impide la satisfacción de un interés sin disminución del patrimonio o cuando se pierde el prestigio profesional o el buen nombre. 
sentido de afectación a su fama, prestigio profesional) ${ }^{30}$. De hecho, últimamente, el Tribunal Supremo tiende a indemnizar dentro del ropaje de los daños morales, las posibles pérdidas patrimoniales que se hayan podido producir en las empresas o sociedades mercantiles ${ }^{31}$, si bien, y esto viene a reafirmar la postura vacilante que mantiene el Supremo, no faltan las sentencias que todavía consideran que la persona jurídica no puede sufrir daños morales, entre otras, STS de 22 de mayo de $2000^{32}$, STS de 11 de septiembre de $2001^{33}$.

\title{
b) Los derechos de la personalidad (honor, intimidad familiar y propia imagen) ${ }^{34}$
}

\begin{abstract}
${ }^{30}$ MARTín DEL Peso, R., "La indemnización y valoración de daños y perjuicios derivados de la responsabilidad civil" en La responsabilidad civil. Aspectos fundamentales, Coord. SEIJAS QuinTANA, J.A., Sepín, Madrid, 2007, pág. 102, manifiesta: "La jurisprudencia estima que la persona jurídica es susceptible de ser protegida en su derecho al honor, si bien de forma más débil y con parámetros diferentes a la persona fisica: STS, Sala $1^{a}$, de 19 de julio de 2006”. El autor añade que el menoscabo que pueda afectar a la buena imagen comercial, es un perjuicio similar, y aunque no equiparable a un verdadero daño moral, debe ser indemnizado.
\end{abstract}

${ }^{31}$ Muy crítico con el TS se ha mostrado al respecto Gómez Pomar, F., "Comentario a la Sentencia del Tribunal Supremo (Sala $1^{\mathrm{a}}$ ), 20.2.2002: el daño moral de las personas jurídicas", InDret 4/2002, www.indret.com, a pesar de reconocer esta realidad. La citada sentencia (RJ 200213501. MP: José Manuel Martínez-Perda Rodríguez) admitió en su FJ $5^{\circ}$ que: "el daño moral es el infringido a la dignidad, a la estima moral y cabe en las personas jurídicas. Ya la añeja sentencia de 31 de marzo de 1930 se refirió en sentido afirmativo a las lesiones al prestigio mercantil de una persona moral o jurídica que sufría la afrenta". El citado autor señala que "la valoración económica de los daños y perjuicios y la construcción en esta materia de criterios razonablemente precisos y, sobre todo, predecibles, son cuestiones demasiado importantes (...) como para esconderlas detrás de categorias ad hoc, como la del daño moral que maneja con excesiva desenvoltura el Tribunal Supremo".

${ }^{32}$ STS (Sala 2a) de 22.5.2000 (RJ 4899 Pte. Sr. Joaquín Delgado García). Según la reseñada sentencia no procede la reparación del daño moral porque "nos encontramos ante unas obligaciones incumplidas de contenido simplemente patrimonial respecto de las cuales no cabe apreciar perjuicios de otro orden que no resulten acreditativos" $\left(F J 6^{\circ}\right)$.

${ }^{33} \mathrm{STS} \mathrm{n}^{\circ}$ 1553/2001 (RJ 7281. Pte. Andrés Martínez Arrieta). Se trataba de la resolución de un caso por delito de estafa y apropiación indebida. Tampoco declara la existencia de daños morales por cuanto no es la vía adecuada $\left(\mathrm{FJ} 11^{\circ}\right)$.

${ }^{34}$ El intento de trazar una línea diferenciadora entre unos derechos y otros pertenece al ámbito de la jurisprudencia, si bien el tema parece estar resuelto a favor de la autonomía de los tres derechos, así lo ponen de manifiesto, STS de 25 de febrero de 2009 (RJ 2009\1624), Pte. Sr. Ignacio Sierra de la Cuesta Gil, que parte del carácter autónomo y del contenido propio y específico de los derechos tres de la personalidad mencionados, o la STC de 2 de julio de 2001 (RTC 2001/156) Pte. Sr. Carles Viver PiSundyer, proclama el carácter autónomo de los derechos garantizados en el art. 18.1 CE, si bien, ésta línea es demasiado fina cuando se refiere a los derechos de la intimidad y la propia imagen; al respecto 
La regulación de los derechos de la personalidad arranca de la actual Constitución Española y aunque con anterioridad a la Norma Fundamental existieron otras leyes que regularon la protección de los derechos fundamentales de la persona, es la LO 1/1982, de 5 de mayo, la que acoge la admisión expresa de daño moral y la procedencia de su resarcimiento $^{35}$. De hecho, a partir de esta Ley Orgánica, la fuente más frecuente de concesión de indemnizaciones por daño moral, es la lesión de estos atributos, puesto que ya se considera una intromisión en los derechos fundamentales ${ }^{36}$. Por citar algunos ejemplos, destacamos: en orden a la protección del honor como derecho fundamental, la sentencia del TSJ del País Vasco de 4 de mayo de $2000^{37}$, la STS de 24 de abril de $2009^{38}$ o STS de 18 de noviembre de $2009^{39}$; en cuanto a la

entiende la jurisprudencia que son autónomos aunque normalmente exista interrelación entre ellos, v.gr., STS 13 de noviembre de 2008 ( $R J$ 2009\407), Pte. Sr. Clemente Auger Liñán, o como dijo en relación a estos dos derechos, YZQuIERdo TOlSADA, M., "Daños a los derechos de la personalidad: (honor, intimidad y propia imagen)" en Tratado de Responsabilidad Civil coord. REgLERo CAMPOS, L.F., T. 3, $4^{a}$ edic., Thomson-Aranzadi, Navarra, 2008, pág. 337, "cuando se trata de personas famosas o con proyección pública es uno de estos puntos que aparecen condenados a navegar en la penumbra más absoluta".

${ }^{35}$ FerRer Vicente, J.M., "La cuestión de los daños morales", Difusión Jurídica y Temas de Actualidad (cuadernos prácticos), Madrid, 2007, pág. 35.

${ }^{36}$ Domínguez Hidalgo, C.A., El daño ..., cit., pág. 371.

${ }^{37}$ (JUR 2001/35510), Pte. Sra. Begoña Orue Bascones. La destacamos porque la indemnización a los daños morales no solamente se concede por el descrédito en el honor que un hombre sufrió al ser detenido ilegalmente delante de sus hijos, mujer y vecinos, sino por el impacto psicológico que sufrió y que la ponente identifica con el daño moral.

38 (RJ 2009/3166), Pte. Sr. Xavier O'Callaghan Muñoz. Indemniza por daños morales a quien fue incluido erróneamente en el registro de morosos de un banco, suponiendo esta inclusión, una intromisión en su honor.

${ }^{39}$ (JUR 2009/474617), Pte. Sr. Xavier O’Callaghan Muñoz. La sentencia indemnizó por los daños morales causados a una persona sobre la que se vertieron una serie de opiniones negativas en distintos programas de televisión, sobre hechos que ocurrieron 25 años atrás, lesionando así, su derecho al honor. 
protección de la propia imagen, destaca la STS de 19 de noviembre de $2008^{40}$; y en relación a la intromisión en la intimidad, reseñamos la STS de 17 de junio de $2004^{41}$.

\section{c) La vida y la integridad física}

La vida como bien supremo del ser humano y la integridad física han sido también objeto de atención por parte de nuestro Alto Tribunal, conceptuando el atentado a las mismas como daño moral, v. gr., por la muerte de un familiar, no sólo por la asistencia moral y afectiva que pudiera prestarles sino también por la ayuda material que su trabajo les reportaba (STS (Sala $2^{\mathrm{a}}$ ) de 12 de noviembre de 1957) o por la pérdida funcional de los dedos (STS de 29 de mayo de 1952) o de la visión (STS de 10 de marzo de 1967).

\section{d) El ámbito psico-afectivo}

Probablemente es la modalidad que más atienden los tribunales, y que en muchas ocasiones se ha identificado con el daño moral "strictu sensu". Dentro de este ámbito tienen cabida desde los sufrimientos físicos hasta las simples molestias, incomodidades o perturbaciones de la tranquilidad ${ }^{42}$. Entre otras múltiples y variopintas sentencias, se han concedido indemnizaciones: por daño moral derivado de la angustia o frustración por la inesperada concepción de un hijo por defecto en el anticonceptivo intrauterino $^{43}$; o por la pérdida de una perra cruzada que resultó atropellada y que

\footnotetext{
40 (RJ 2008\6055), Pte. Sr. Ignacio Sierra Gil de la Cuesta. Indemniza a los padres de dos menores de corta edad por la publicación de la fotografía de sus hijos que se encontraban en la Feria de Sevilla, vestidos de flamencos e iniciando el gesto de besarse. El diario utilizaba la fotografía con fines publicitarios, y sin que existiera consentimiento de los padres, ni interés cultural o accesoriedad de la imagen.

41 (RJ 2004\3628). Pte. Sr. Rafael Ruiz de la Cuesta Cascajares. Indemnizó por los daños morales causados al haberse publicado la fotografía con fines eróticos, de una mujer desnuda, que aunque aparecía con la cara tapada, y que resultaba identificable en su entorno.

${ }^{42}$ GARCÍA LóPEZ, R., Responsabilidad civil ..., op. cit., pág. 86.

${ }^{43}$ STS de 24 de septiembre de 1999 (RJ 1999\7272).Pte. Excmo Sr. Alfonso Villagómez Rodil.
} 
carecía de valor en el mercado ${ }^{44}$; también por las injurias que trajeron como consecuencia trastornos psiquiátricos ${ }^{45}$; por los ruidos y malos olores procedentes de una carnicería $^{46}$; por no tener ascensor a persona de edad y enferma que vive en la quinta planta $^{47}$; incluso por pérdida de la calidad de vida aun sin haberse producido enfermedad debido a la producción de inmisiones y agresiones ambientales ${ }^{48}$; también por la preocupación y desasosiego sufridos por los propietarios cuando conocieron que su vivienda estaba embargada e iba a ser subastada ${ }^{49}$; por las molestias sufridas por propietario y morador de vivienda afecta a ruidos ${ }^{50}$; por las horas de tensión, incomodidad y molestias producidas por demora de ocho horas en el transporte aéreo ${ }^{51}$ o por retraso de vuelo y consiguiente estancia en aeropuerto durante toda la noche sin asistencia de la compañía aérea $^{52}$; por la pérdida de una maleta en viaje de ida a lugar lejano en la que se incluían medicinas ${ }^{53}$; por el desasosiego, inquietud y alarma social que produce en los ciudadanos la ocupación de edificios sin autorización produciendo además desórdenes públicos ${ }^{54}$; por la zozobra e inquietud por el rápido deterioro de una vivienda cuyo vendedor ocultó desperfectos ${ }^{55}$; por la frustración de los derechos de defensa y pérdida de las expectativas procesales $^{56}$; por la incomodidad de tener que reiterar quejas y dedicarse a la búsqueda de pertenencias en tiempo vacacional ante la

\footnotetext{
${ }^{44}$ SAP de Oviedo de 16 de noviembre de 1999. Pte. Sr. José Ignacio Álvarez Sánchez.

${ }^{45}$ SAP de Álava de 22 de octubre de 1999. Pte. Sr. Julián Sánchez Melgar.

${ }^{46}$ SAP de Asturias de 14 de septiembre de 1993 (AC 1993\1631). Pte. Frco. Luces Gil.

${ }^{47}$ SAP de Málaga de 15 de octubre de 1998. Pte. Sr. Frco. J. Arroyo Fiestas.

${ }^{48}$ STS de 2 de febrero de 2001 (RJ 2001\1003), Pte. Sr. Luis Martínez Calcerrada.

${ }^{49}$ SAP de Navarra de 27 de junio de 1996 (AC 1996|1189).Pte. Sr. José J. Huarte Lázaro.

${ }^{50}$ STS de 31 de mayo de 2007 (RJ 2007\3431). Pte. Frco. Marín Castán.

${ }^{51}$ STS de 31 de mayo de 2000 (RJ 2000\5089), Pte. Jesús Corbal Fdez.

${ }^{52}$ SAP de Las Palmas de 16 de septiembre de 2005 (AC 2005\1682), Sra. Mónica Ga de Yzaguirre.

${ }^{53}$ SAP de Pontevedra de 19 de julio de 2007 (AC 2007\2237), Sr. Frco. Javier Menéndez Estévanez.

${ }^{54}$ STS (Sala de lo Criminal) de 30 de enero de 1984 (RJ 1984\431), Pte. Benjamín Gil Sáez.

${ }^{55}$ SAP de Navarra de 9 de febrero de 2001 (JUR 2001\135405), Sr. Álvaro Latorre López.

${ }^{56}$ STS de 28 de abril de 2005 (RJ 2005\2646). Pte. Sr. Román Ga Varela.
} 
pérdida de equipaje ${ }^{57}$; incluso por la impotencia y frustración que produce el incumplimiento respecto a las calidades y servicios de un hotel contratado previamente a través de agencia ${ }^{58}$; por las molestias y trastornos que produce la actuación de un menor que accedió a los datos personales y bancarios de una persona ${ }^{59}$; por la agravación de trastorno de somatización y de personalidad histérica grave ante el incumplimiento por parte de un procurador de sus deberes de representación en juicio de desahucio ${ }^{60}$; o por soportar las pésimas condiciones de habitabilidad de una vivienda $^{61}$, etc., etc. Como se puede observar la lista de sentencias que resarcen el daño moral es copiosa y sin "numerus clausus". Este criterio aperturista de los tribunales ha llevado a los mismos a considerar dentro del daño moral nuevos supuestos que hace unos años serían imposibles de encajar dentro de esta figura por ejemplo, como el causado por la pérdida de oportunidad ${ }^{62}$.

\section{e) Otras categorías o modalidades admitidas}

${ }^{57}$ SAP de Alicante de 7 de octubre de 2004 (AC 2004\1995), Sra. Cristina Trascasa Blanco.

${ }^{58}$ SAP de Guadalajara de 4 de febrero de 2005 (AC 2005\493), Sra. Isabel Serrano Frías.

${ }^{59}$ SAP de Salamanca de 5 de febrero de 2009 (JUR 2009\295151). Sr. Ildefonso Ga del Pozo.

${ }^{60}$ SAP de Barcelona de 30 de marzo de 2005 (JUR 2005\115132). Sr. E. Alavedra Farrando.

${ }^{61}$ SAP de Las Palmas de 11 de mayo de 2005 (JUR 2005\166532). Sra. R. Fdez. Alaya.

62 STS de 14 de mayo de 1999 (RJ 1999\3106), Pte. Sr. Alfonso Barcalá Trillo-Figueroa. Trataba el supuesto de un abogado que llevó vía penal la defensa de los intereses de los padres de un menor que había fallecido ahogado en una piscina municipal. El asunto fue sobreseído provisionalmente en la jurisdicción penal; el letrado aconsejó a sus clientes no recurrir el auto de sobreseimiento y evitó asesorarles sobre la posibilidad de defender sus intereses en el orden civil (daño moral irrogado). 
Con el fin de dar cobertura al resarcimiento integral del daño, conforme a lo establecido en el artículo 11 de la Resolución 75/7 del Comité de Ministros del Consejo de Europa ${ }^{63}$, se han ido admitiendo otra serie de daños morales gracias a los esfuerzos de la doctrina francesa: el llamado pretium doloris, el perjuicio estético, el perjuicio de afecto y la pérdida de agrado $^{64}$. Este tipo de daños extrapatrimoniales estarían comprendidos en la idea de daño corporal ${ }^{65}$.

En cuanto al pretium doloris debemos entenderlo como la reiteración terminológica del daño moral con alguna matización ${ }^{66}$ puesto que su indemnización trata de compensar los malos ratos, las depresiones que el daño produce a la salud ${ }^{67}$. Al respecto, muy ilustrativas son las sentencias del Tribunal Supremo (Sala de lo Contencioso-administrativo) de 23 de febrero de 1988, por los sufrimientos físicos y psíquicos producidos por seis sucesivas intervenciones quirúrgicas a consecuencia de unos disparos por la Fuerza Pública) ${ }^{68}$, o la STS de 4 de abril de 1989 en relación al sufrimiento psico-físico como consecuencia de una neumonía contraída en residencia militar $^{69}$.

\footnotetext{
${ }^{63}$ Literalmente manifiesta: "la víctima debe ser indemnizada del perjuicio estético, de los dolores físicos $y$ de los sufrimientos psíquicos. Esta última categoría comprende, en cuanto concierne a la víctima, diversas perturbaciones y desagrados tales como malestares, insomnios, sentimiento de inferioridad, una disminución de los placeres de la vida causados especialmente por la imposibilidad de dedicarse a ciertas actividades de agrado".

${ }^{64}$ YzQuierdo Tolsada, M., Sistema de ..., op. cit., pág. 160.

${ }^{65}$ Diez-Picazo, L., Derecho de daños, Civitas, Madrid, 2000, pág. 327; Al respecto, señala VicenTe DoMINGO, E., Los daños corporales: tipología y valoración, José M $\backslash$ Bosch Editor, S.A. Barcelona, 1994, pág. 196, que es muy difícil extraer un concepto de daño moral puro porque siempre se encuentra relacionado con otras manifestaciones del daño corporal.

${ }^{66}$ Marcos Oyarzun, F.J., Reparación integral del daño. El daño moral, Bayer Hnos., S.A., Barcelona, 2002, págs. 102-103.

${ }^{67}$ Vicente Domingo, E., Los daños corporales ... cit., pág. 196.

${ }^{68}$ (RJ 1988\1451), Pte. Sr. Pedro Antonio Mateos García.

${ }^{69}$ (RJ 1989 2808), Pte. Sr. Enrique Cancer Lalanne.
} 
El perjuicio estético (préjudice esthétique) tiene la ventaja de que puede probarse por sí mismo, y el término que lo define fundamentalmente es "deformidad". Es el estigma o tara fisiológica que afecta a la anatomía exterior de manera duradera: cicatrices, pérdidas de sustancia, de cabellos, de dientes, costurones, manchas, malformaciones, pérdida de euritmia, etc ${ }^{70}$. En esta línea nos encontramos la STS de 20 de enero de $1998^{71}$ que resuelve un supuesto en orden a la indemnización por las lesiones que las fuerzas de seguridad produjeron a un estudiante, en una manifestación, entre otras, pérdida de la visión de un ojo.

El denominado perjuicio de afecto (préjudice d'afection) sirve para designar el daño moral que algunas personas vinculadas a la víctima sufren ante el dolor o la muerte del agraviado, últimamente también se ha incluido, la pérdida de una cosa a la que se considera cercana ${ }^{72}, v . g r$., referida al primer caso, destaca la célebre SAT de Granada de 21 de enero de $1972^{73}$.

La pérdida del agrado (préjudice d'agrement) hace referencia al daño conocido en Italia como danno alla vita di relazione. Al principio, se designaba a la privación de la posibilidad de ejercer determinadas actividades en las cuales la víctima sobresalía, ya fueran deportivas o culturales, más tarde y con el fin de superar esta concepción tan elitista se definió como el referido a la pérdida de goces y alegrías que se pueden esperar de una existencia normal (lavarse, vestirse, pasear...) ${ }^{74}$. Un caso representativo es el resuelto por el TSJ de Aragón el 22 de marzo de $2003^{75}$, que gira en torno a la

\footnotetext{
${ }^{70}$ Vicente Domingo, E., Los daños corporales ... cit., pág. 203.

${ }^{71}$ (RJ 1998\350), Pte. Juan Antonio Xiol Ríos.

${ }^{72}$ BARrientos ZAMORANO, M., El resarcimiento ..., op. cit., pág. 71.

73 Conocida como "el caso de los novios de Granada". Esta famosa sentencia representa un hito fundamental en la trayectoria de la jurisdicción contenciosa de nuestro país, puesto que por primera vez se enfrenta al daño moral y concede una indemnización tanto a los padres como a la novia del joven fallecido en accidente "por la pena que produce la pérdida de un ser querido entre sus familiares y las personas en trance de serlo". Así lo reseña, MARCOS OYARZUN, F.J., "Integridad en la reparación administrativa del daño", Revista Valenciana D'Estudios Autonómics, n 35, Valencia, 2001,págs. 51-54

${ }^{74}$ Diez-PiCAZO, L., Derecho de ... op. cit., pág. 327; ViCEnTE Domingo, E., Los daños corporales ... cit., págs. 195 y ss., YZQUIERdo TOLSADA, M., Sistema de ..., op. cit., pág. 161.

75 (RJ 2000\1239), Pte. Sr. Jesús M ${ }^{\text {a }}$ Arias Juana.
} 
indemnización a los padres de un menor que sufrió graves lesiones cuando en un espectáculo una res saltó una valla. Las heridas fueron de tal entidad que le supusieron limitaciones en su vida personal. En este caso confluyeron además otros perjuicios por lo que la indemnización se concedió también por lesiones físicas, psíquicas y perjuicio estético.

Otros autores, como DIEZ- PICAZO señalan una modalidad más, a saber, la del denominado perjuicio sexual, que comprendería la imposibilidad de mantener relaciones o de $\operatorname{procrear}^{76}$. En esta línea reseñamos la STS de 14 de febrero de $2006^{77}$ por la que se indemniza a una mujer que tras un diagnóstico erróneo se le extirpa una trompa de falopio, limitando la procreación a la inseminación artificial.

Hay que precisar, que es muy difícil delimitar claramente las características de unos y otros supuestos o tipos de daños morales porque si ya la frontera entre el daño moral y el material es a veces difusa, el problema se agrava con la proliferación de tantas modalidades de daños donde a veces el mismo daño podría encajar en varias categorías $^{78}$.

\subsubsection{EL CONCEPTO DE DAÑO MORAL SEGÚN ALGUNAS SENTENCIAS}

Las únicas sentencias que, desde 1902 hasta principios de los años setenta, definían expresamente el daño moral, son las sentencias del Tribunal Supremo de 28 de febrero de 1959 y la de 28 de febrero de 1964, que reitera el contenido de aquella ${ }^{79}$, ambas basadas en la lesión de bienes de la personalidad.

\footnotetext{
${ }^{76}$ DieZ-PiCAZO, L., Derecho de ... op. cit., pág. 327.

77 (RJ 2006\884), Pte. Juan Antonio Xiol Ríos.

${ }^{78}$ YzQuierdo Tolsada, M., Sistema de ..., op. cit., pág. 162.

${ }^{79}$ García Serrano, F. A., “El daño moral ...”, cit., pág. 810; GARCÍA LÓPEZ, R., Responsabilidad civil ..., op. cit., págs. 88 y ss; SANTOS BRIZ, J., La responsabilidad ..., op. cit., pág. 166.
} 
Para la sentencia de 28 de febrero de 1959 "el concepto de daño moral, tal y como ha sido perfilado por la jurisprudencia, está constituido por los perjuicios que sin afectar a las cosas materiales, susceptibles de ser tasadas, tanto en su totalidad como parcialmente en los diversos menoscabos que puedan experimentar, se refieren al patrimonio espiritual, a los bienes inmateriales de la salud, el honor, la libertad y análogos que son los más estimados, y por ello más sensibles, más frágiles y más cuidadosamente guardados, bienes morales que al no ser evaluables dinerariamente para resarcimiento del mal sufrido cuando son alterados, imposible de lograr integramente, deben, sin embargo, ser indemnizados discrecionalmente en función del artículo 1902 del citado Cuerpo legal, como compensación a los sufrimientos del perjudicado ...".

Varios son los logros de esta sentencia: primero, porque hace hincapié en el carácter de extrapatrimonialidad de los daños morales; segundo, porque resalta la imposibilidad de que sean valorados económicamente; y por último, es de destacar que hace coincidir el daño moral con la lesión de los bienes jurídicos de la personalidad. Por el contrario, aflora la confusión del Supremo cuando alude a la reparación de los sufrimientos del perjudicado puesto que al asignar a la indemnización la función de reparar los sufrimientos, está haciendo recaer sobre éstos y no sobre la lesión a los bienes o derechos de la personalidad, el objeto del daño moral ${ }^{80}$.

Esta confusión también se pone de relieve en la sentencia de 28 de febrero de $1964^{81}$ que reiterando la definición de la anterior sentencia, además matiza el concepto al distinguir entre dolor físico (derivado de las lesiones a la integridad física) y el dolor moral (cuyo contenido omite), lo cual significaría que los dolores y sufrimientos de carácter físico o corporal no serían objeto de daños morales, contradiciéndose una vez más, en la noción de daño moral ${ }^{82}$; otros, opinan que el mayor fallo está en reducir al

\footnotetext{
${ }^{80}$ GARcía LÓPEZ, R., Responsabilidad civil ..., op. cit., págs. 89-90.

${ }^{81}$ La sentencia aludida se refiere a la indemnización que solicitaron unos nacionales franceses que se encontraban de turismo por España, y que como consecuencia de un accidente de tráfico, vieron frustradas sus vacaciones.

${ }^{82}$ GARCÍA LÓPEZ, R., Responsabilidad civil ..., op. cit., págs. 90-91.
} 
daño moral a la mínima expresión ya que el contenido del perjuicio moral quedaría vacío $^{83}$.

Importantes son también las sentencias del Tribunal Supremo de 7 de febrero de 1962 y de 24 de noviembre de 1970. Si bien estas sentencias no definen expresamente el daño moral, sí lo hacen de modo indirecto, refiriéndose al perjuicio moral configurado por los sufrimientos o padecimientos del ánimo ${ }^{84}$. La primera de ellas, señala que: “aunque los derechos de la personalidad no se acomodan a una estimación pecuniaria (...) la víctima del perjuicio moral padece dolores y la reparación sirve para restablecer el equilibrio roto ("pretium doloris"), pudiendo gracias al dinero (...), procurarse sensaciones agradables que vendrán a contrapesar las dolorosas o desagradables $" 85$; la segunda resolución viene a superar en parte el fallo de la anterior en orden a tener en cuenta el carácter de extrapatrimonialidad de este tipo de daños así reza: "el perjuicio o daño moral, al que caracteriza su extrapatrimonialidad o contenido no económico, mostrándose por afectar a los sentimientos bien del propio interesado o al de otros, como lo es, el que puede producir la muerte de una persona querida",86.

Dentro de esta forma indirecta de conceptuar el daño moral encontramos otras sentencias que identifican los daños morales con "los que afecten a la pérdida de la vida, integridad corporal... $" 87$.

A partir de los años setenta, los intentos jurisprudenciales por conceptualizar el daño moral se ven incrementados, si bien son siempre reiteraciones de las teorías

\footnotetext{
${ }^{83}$ GarCía Serrano, F. A., "El daño moral ...", cit., pág. 809. En cuento que el daño moral no se integraría ni por la lesión a los derechos de la personalidad, ni los sufrimientos físicos ni la frustración del viaje.

${ }^{84}$ GARCÍA LÓPEZ, R., Responsabilidad civil ..., op. cit., págs. 92-93.

${ }^{85}$ SANTOS BRIZ, J., La responsabilidad ..., op. cit., pág. 167.

${ }^{86}$ GARCÍA LÓPEZ, R., Responsabilidad civil ..., op. cit., págs. 92-93. El autor basa su crítica en que finalmente esta sentencia reduce el carácter de extrapatrimonialidad de estos daños, a la lesión de los sentimientos.
}

${ }^{87}$ Cfr. STS de 2 de diciembre de 1946. 
aportadas por la doctrina, acomodadas al supuesto que resuelven. A modo de ejemplo, señalaremos algunas de ellas, que por su interesante contenido vienen a resumir el panorama jurisprudencial en cuanto al objeto de investigación que nos ocupa. En esta línea, destaca la STS (Sala de lo Penal) de 10 de noviembre de $1979^{88}$ que identifica los daños morales con el llamado "pecunia doloris" o sufrimientos o padecimientos tanto físicos como morales experimentados por el ofendido como consecuencia de las graves lesiones, heridas o fracturas sufridas.

Años más tarde, la STS de 25 de junio de $1984^{89}$ viene reflejar el predominio de la concepción de los perjuicios morales basada en el ámbito psico-afectivo: “Aunque dicha figura no se encuentre específicamente nominada en el Código Civil, tiene adecuado encaje en la exégesis de ese amplísimo "reparar el daño causado» que emplea en su artículo 1902, como tiene declarado esta Sala a partir de la sentencia de 6 de diciembre de 1912; La construcción del referido daño como sinónimo de ataque o lesión directos a bienes o derechos extrapatrimoniales o de la personalidad, peca hoy de anticuada y ha sido superada tanto por la doctrina de los autores como de esta Sala; Así, actualmente, predomina la idea del «daño moral» representado por el impacto o sufrimiento psíquico o espiritual que en la persona pueden producir ciertas conductas, actividades o, incluso, resultados, tanto si implican una agresión directa o inmediata a bienes materiales, cual si el ataque afecta al acervo extrapatrimonial o de la personalidad (ofensas a la fama, al honor, honestidad, muerte de persona propietario, etc.); De ahí que, ante, frente o junto a la obligación de resarcir que surge de los daños patrimoniales, traducido en el resarcimiento económico o dinerario del «lucro censans» y/o del «damnum emergens», la doctrina jurisprudencial haya arbitrado y dado carta de naturaleza en nuestro derecho a la reparación del daño o sufrimiento moral, que si bien no atiende a la reintegración de un patrimonio, va dirigida, principalmente, a proporcionar en la medida de lo humanamente posible una satisfacción como compensación al sufrimiento que se ha causado-sentencia de 31 de mayo de 1983 (_RJ1983\2956) y las en la misma citadas”.

Por su parte, la Sala de lo Penal del Alto Tribunal ha esbozado alguna noción de lo que debemos entender por perjuicios morales, en este sentido es importante el

\footnotetext{
${ }^{88}$ (RJ 1979\3880), Pte. Sr. Luis Vivas Marzal.

${ }^{89}$ (RJ 1986\1145), Pte. Sr. Mariano Martín-Granizo Fernández.
} 
análisis que realiza la STS (Sala de lo Penal) de 29 de junio de $1987^{90}$ que distingue entre: daños morales indirectamente económicos (por ejemplo, la disminución de la clientela a consecuencia del descrédito consecutivo a la imputación, a la expresión o a la acción), y los estrictamente morales (como el ansia, la inquietud, la preocupación, el deshonor, la tristeza, la melancolía, con tal que hayan sido consecuencia natural de la infracción).

La interpretación del daño moral por parte de la jurisprudencia no ha sido muy distinta en los últimos tiempos, destacando siempre la idea del "impacto o sufrimiento físico o espiritual que en la persona pueden producir ciertas conductas, actividades o resultados, (...) tanto si implican una agresión a los bienes materiales como si el ataque afecta al acervo extrapatrimonial o de la personalidad; junto a ello, no hay que olvidar que el daño es causar un detrimento, perjuicio, menoscabo, dolor o molestia ..." Otras veces, para definir el daño moral señala las diversas situaciones en las que tiene cabida la indemnización por este tipo de perjuicios: "sufrimiento o padecimiento psíquico o espiritual (STS 23.7.1990), impotencia, zozobra, ansiedad, angustia (STS 6.7.1990), sensación anímica de inquietud, pesadumbre, temor o presagio de incertidumbre (STS 22.5.1995), impacto emocional, incertidumbre consecuente (STS 27.1.1998)." 92

Finalmente, por la amplia definición del daño moral que realiza destacamos una sentencia dictada por la Audiencia Provincial de Salamanca en fecha 5 de febrero de $2009^{93}$, que aunque reiterando la anterior sentencia, viene a resumir en gran medida, todo el pensamiento y la evolución de la jurisprudencia de los últimos tiempos, conforme hemos tratado de sintetizar a lo largo de estas líneas. De este modo, la Audiencia salmantina se pronuncia arguyendo: "La doctrina jurisprudencial ha venido

90 (RJ 1987\5018), Pte. Sr. Luis Vivas Marzal. Identifica los daños morales con “«pecunia doloris» es decir, el de los sufrimientos o padecimientos de la víctima experimentados en el curso de su curación o como consecuencia de las secuelas resultantes, el del «doloroso vacio», pérdida del ser querido o ruptura de la convivencia y de los sentimientos familiares respecto al pariente próximo fallecido, el del sentimiento de la dignidad lastimada o vejada, el del deshonor, desprestigio, deshonra o descrédito consecutivos a la injuria o a la calumnia, o, finalmente, el de la traumatización y cambio de personalidad de la mujer que ha sufrido un atentado contra su libertad sexual..."

${ }^{91}$ SAP de Ciudad Real de 21 de septiembre de 1995

${ }^{92}$ STS de 31 de mayo de 2000 (RJ 2000\5089), Pte. Jesús Corbal Fdez.

${ }^{93}$ SAP de Salamanca de 5 de febrero de 2009 (RJ 2009\295151), Pte. Sr. Ildefonso García del Pozo. 
a establecer que la situación básica para que pueda darse lugar a un daño moral indemnizable consiste en un sufrimiento o padecimiento psíquico (SSTS. de 22 de mayo de 1.995, 19 de octubre de 1.996 y 24 de septiembre de 1.999), y como tal se ha referido al impacto psíquico o espiritual (STS. de 23 de julio de 1.990 ), impotencia, zozobra, ansiedad, angustia (STS. de 6 de julio de 1.990 ), la zozobra, como sensación anímica de inquietud, pesadumbre, temor o presagio de incertidumbre (STS. de 22 de mayo de 1.995 ), el trastorno de ansiedad, impacto emocional, incertidumbre consecuente (STS. de 27 de enero de 1.998 ), impacto, quebranto o sufrimiento psíquico (SSTS. de 12 de julio de 1.999 y de 31 de mayo de 2.000 ). Conforme señaló ya la STS. de 25 de junio de 1.984 , en el momento actual predomina la idea del daño moral, representado por el impacto o sufrimiento psíquico o espiritual que en la persona pueden producir ciertas conductas, actividades o, incluso, resultados, tanto si implican una agresión directa o inmediata a bienes materiales, como si el ataque afecta al acervo extramatrimonial o de la personalidad, y por ello la reparación del daño moral, si bien no atiende a la reintegración del patrimonio, va dirigida, principalmente, a proporcionar en la medida de lo humanamente posible, una satisfacción como compensación al sufrimiento que se ha causado. Y asimismo ha establecido la doctrina jurisprudencial que en la indemnización por daños morales su valoración no puede obtenerse de una prueba objetiva, sino que a tal efecto han de tenerse en cuenta y ponderarse las circunstancias concurrentes en cada caso (STS. de 19 de octubre de 2.000)".

\section{CONCLUSIONES}

Son muchas las teorías que tratan de conceptualizar el daño moral. Aún en la actualidad se siguen produciendo debates doctrinales sobre lo que se debe entender por daño moral, probablemente la abstracción del término sea la causa. Lo cierto es que la autonomía del daño moral y su admisión por los tribunales (desde el año 1912) resulta incuestionable, al igual que su resarcimiento. Distinta cuestión es la que deriva de los problemas en relación al quantum indemnizatorio o los que se generan en torno a la forma de reparación, que en definitiva, queda en manos del arbitrio judicial, o incluso, la dificultad de probar su existencia, donde el papel de los abogados es primordial.

En cuanto a la noción de daño moral según el criterio jurisprudencial hay que concluir señalando que nuestro Tribunal Supremo no da una definición de daño moral, 
puesto que a diferencia de la doctrina, evita exponer teorías o criterios, salvo excepciones. Su aportación es meramente práctica, y aunque son numerosas las sentencias en las que el Alto Tribunal y nuestras audiencias analizan la cuestión de los daños morales, la mayoría se limitan a resolver el caso planteado, con una clara propensión a enumerar los supuestos más significativos en relación a los bienes protegidos y a ampliar el ámbito de este tipo de daños.

Por su parte, la tendencia doctrinal actual es a la vinculación de este tipo de perjuicios con los derechos de la personalidad o extrapatrimoniales, con la esfera psicofísica del individuo, con los sufrimientos, con el dolor ... Hoy en día, resulta insuficiente considerar que el daño moral o no patrimonial es todo aquello que no es daño material o patrimonial, y de tener que inclinarnos por un concepto de daño moral, en términos generales, sería por el concepto que acertadamente expone el profesor DIEZ-PICAZO en alusión a la teoría de MARTÍN CASALS, para quien los daños morales son los infligidos a los derechos de la personalidad o extrapatrimoniales. Distinguiendo dos aspectos: uno interno, referido a la esfera interna del sujeto (dolor, angustia, etc), y otro externo, que se concreta en la disminución de las posibilidades de relación con el mundo exterior. Señalando que el daño moral sería "la afectación de la esfera sicofisica que es consecuencia de la lesión de un derecho o bien de la personalidad" $" 94$. Todo ello, sin perjuicio de ser matizada, por ejemplo, en el caso de perjuicios causados a las personas jurídicas, que entendemos deben ser indemnizables siempre que afecten al buen nombre, reputación, o buena fama.

${ }^{94}$ DieZ-PiCAZo, L., El escándalo del daño moral, Thomson- Civitas, Pamplona, 2008, págs. 91-92. 